\title{
Trajetórias compartilhadas: experiências de estudantes, usuários e familiares de serviços de saúde mental em ações de ensino- aprendizagem em saúde
}

\author{
Shared trajectories: experiences of students, users and family \\ members of mental health services in teaching-learning actions in \\ health
}

Maria Ines Badaró Moreira1

DOI: $10.1590 / 0103-1104202012718$

RESUMO Este artigo tem como objetivo analisar o protagonismo de pessoas com sofrimento psíquico intenso nas ações de ensino-aprendizagem em saúde, componente fundamental de atividades no âmbito do tripé universitário. Trata-se de estudo de caso sobre espaço de compartilhamento de saberes sobre saúde mental, que revela a importância do saber da experiência no espaço acadêmico e destaca modos de aprender e ensinar sobre as diferentes nuances do viver o sofrimento psíquico intenso em liberdade. Destaca os efeitos dessas ações para os participantes, com ênfase na promoção de debate sobre a luta constante pela garantia de direitos humanos no campo da saúde mental, e, com isso, aponta para o engendramento de novas formas de convívio e trocas sociais. Conclui-se que a experiência de aprender-ensinar sobre o campo da saúde mental, com a participação de usuários e familiares, vem transformando a concepção de cuidado, de integralidade e o sentido do trabalho em saúde.

PALAVRAS-CHAVE Saúde mental. Capacitação profissional. Educação em saúde. Usuários.

\begin{abstract}
This article aims to analyze the role of people with intense psychological distress in the teachinglearning actions in health, a fundamental component of activities within the scope of the university tripod. It is a case study about a space for sharing knowledge about mental health, which reveals the importance of knowing the experience in the academic space and highlights ways of learning and teaching about the different nuances of experiencing intense psychological suffering in freedom. It highlights the effects of these actions for participants, with an emphasis on promoting debate on the constant struggle for the guarantee of human rights in the field of mental health, and, with that, points to the creation of new forms of social interaction and exchanges. It is concluded that the experience of learning-teaching about the field of mental health, with the participation of users and family members, has been transforming the concept of care, integrality and the meaning of health work.
\end{abstract}

KEYWORDS Mental health. Professional training. Health education. Users. 


\section{Introdução}

A formação em saúde sustentou-se em sólidas raízes no modelo de homem biológico, com consequente esvaziamento do sentido do sofrimento psíquico. $\mathrm{O}$ momento denominado como a grande internação ${ }^{\mathbf{1}}$ inaugurou uma abordagem aos transtornos pautada na observação, sistematização e na busca de tecnologias de tratamento e remissão dos sintomas do que foi denominado como doença mental. $\mathrm{Na}$ mesma via de compreensão, o nascimento da clínica $^{2}$ fortaleceu o diagnóstico e as intervenções silenciadoras das expressões da loucura que perduram até os dias atuais ${ }^{3}$.

Esse modo de funcionar se fortaleceu nos últimos duzentos anos, sob a influência de relações de poder subvertidas na compreensão das síndromes ou dos transtornos psiquiátricos em busca da cura. $\mathrm{O}$ silenciamento da loucura contribuiu para o desaparecimento do homem, coisificado, sob diagnósticos psiquiátricos equivalentes a um etiquetamento ${ }^{4}$. Seu efeito transcende a esfera psiquiátrica e atinge diversas instituições da violência ${ }^{5}$, sustentadas na organização societal excludente e seletiva. Neste sentido, o hospital psiquiátrico se tornou local privilegiado para produção de um campo específico de saber considerado científico, que se tornou modo hegemônico de tratamento ${ }^{2}$, cindindo o saber sobre a loucura da experiência vivida pela pessoa.

A separação entre o conhecimento e a experiência da loucura legitimou a Psiquiatria como supremacia de saber e fez com que as intervenções se tornassem também expressão de um saber-poder ${ }^{2}$ em nome do tratamento. Considerado inapropriado para o convívio, o sujeito foi silenciado, a experiência trágica, a frustração, o fracasso, o sofrimento em geral foram se afastando do cotidiano das pessoas e passaram a ser nomeados como categorias psicopatológicas ${ }^{6}$. A partir da consolidação do hospital psiquiátrico como o lugar para a loucura ${ }^{1}$, o exercício do saber-poder espraiou-se para os técnicos e para a equipe ${ }^{7,8}$.
Para Franco Basagliaa, ${ }^{4,5}$ a história da loucura no ocidente é a história de um sistema de poder sobre o qual está fundamentada a organização capitalista de nossa sociedade. Para a manutenção e o exercício do poder, coube aos técnicos criarem formas de violência mistificadas através de seus tecnicismos, cuja função é ampliar a distância e as fronteiras da exclusão ${ }^{5}$. Tratase da confirmação do monólogo psiquiátrico sobre a loucura, retratado pelo desprezo dessa experiência também como um saber.

Nesse monólogo, está implícito o silenciamento da loucura ${ }^{2}$ e de suas expressões, a desqualificação de sua linguagem e seu modo de agir, a infantilização de seus atos e a desconsideração de suas opiniões. As intervenções hegemônicas nesse campo foram forjadas a partir da destituição do valor do louco como cidadão, inseridas em espaços excludentes e instituições de violência ${ }^{5}$. Por isso, a instituição a ser negada, para além do hospital psiquiátrico como arquitetura e seus muros em si, é aquela em que a "violência é exercida por aqueles que empunham a faca contra os que se encontram sob sua lâmina"5(101). Trata-se de um modo de se relacionar que coloca o homem entre parênteses ${ }^{9}$, a fim de analisar, sistematizar e interpretar seu sintoma. Esse tipo de instituição se fortaleceu e avançou, ao longo dos anos, no sentido de silenciar a expressão da loucura.

Ao anunciar que violência e exclusão estão na base das relações sociais, a desinstitucionalização convoca à reflexão sobre as dispersas situações em que impera a violência, sugerindo que a supremacia do saber técnico pode mantê-la ao oprimir e desqualificar o conhecimento advindo do mundo das pessoas consideradas loucas. Neste sentido, é imperativo buscar possibilidades de construir novos modos de produzir conhecimento que impliquem estabelecer relações menos hierarquizadas, em que o cuidado se torne o pilar para práticas desinstitucionalizantes ${ }^{9}$. Essas transformações demandam a necessidade de reconstruir o objeto de trabalho que o saber psiquiátrico simplificou e objetivou. 
Ao colocar o homem entre parênteses 9 para analisar, sistematizar e interpretar seu sintoma, tomou-se como tarefa desvalorizar e negativar a expressão da loucura em busca de tratamentos. Em oposição, ao apreender a loucura como condição humana, coloca-se a própria loucura entre parênteses em exercício de escuta e compreensão do modo de viver a condição de sofrimento, sem prescindir de entender os seus efeitos cotidianos.

A partir do paradigma desinstitucionalizante $^{9}$, o trabalho em saúde mental pretende reconstruir o objeto da saúde mental que foi simplificado pelo modo de valorizar o conhecimento produzido sobre as pessoas, em busca de devolver sua complexidade na compreensão do sofrimento humano. Para isso, faz-se necessária uma aproximação com a loucura, de modo menos verticalizado. Ao mesmo tempo, devolver a complexidade da loucura significa ampliar o leque de estratégias e ações necessárias para enfrentar os desafios de viver e ser cuidado em serviços que garantam sua liberdade. É necessário compreender o efeito negativo das instituições da violência ${ }^{5}$ para insurgir uma instituição a ser inventada ${ }^{10}$, e, nesse sentido, a formação para o trabalho em saúde deve, também, ser revisitada.

Para isso, a formação para o trabalho em saúde deve ser convocada a transformar o modo de olhar e fazer em saúde, a partir da reconstrução de um novo objeto para a saúde mental. Com esse compromisso, foi elaborado o Projeto de extensão 'Trajetórias: protagonismo de usuários de serviços de saúde mental nas ações de ensino-aprendizagem em saúde’11, no âmbito de uma Universidade Federal vocacionada para formação de profissionais de saúde a partir da integralidade e do trabalho interprofissional ${ }^{12}$. Ao longo de mais de cinco anos, usuários, familiares e estudantes são inseridos em diferentes momentos para trocas de conhecimento e experiência. Foram tomadas como inspiração as diversas experiências em que os usuários de serviços de saúde mental são convidados a participar ativamente da formação ${ }^{13,14}$ e, também, das pesquisas ${ }^{15-17}$.
Este artigo tem como objetivo analisar o protagonismo de pessoas com sofrimento psíquico intenso nas ações de ensino-aprendizagem em saúde, componente fundamental de atividades no âmbito do tripé universitário.

\section{Material e métodos}

O método qualitativo foi utilizado, e, para análise, foram destacados os temas relevantes $^{18}$. Tomou-se como estudo de caso $^{19} \mathrm{O}$ Projeto de extensão Trajetórias. Durante o período de três anos, foram realizadas entrevistas com todos os participantes, e, ao final de cada ano, ocorreu um grupo focal com alunos extensionistas e participantes externos, com vistas à análise dessa inserção e dos seus possíveis efeitos para a formação em saúde. As entrevistas foram gravadas e transcritas, assim como o conteúdo dos grupos focais. Todas as pessoas envolvidas assinaram o Termo de Consentimento Livre e Esclarecido.

Para este manuscrito, também foram reunidas informações de relatórios anuais do Projeto de extensão, registros de atividades, fragmentos de diários de campo e produções coletivas. O material coletado foi organizado por ordem cronológica e por tipo de atividade realizada. Em seguida, procedeu-se à análise temática ${ }^{18}$, que consiste em descobrir núcleos de sentido nos documentos analisados, cuja presença contribua para o objeto analisado.

A pesquisa sobre protagonismo de usuários de serviços de saúde mental nas ações de ensino-aprendizagem em saúde foi aprovada pelo Comitê de Ética da instituição de ensino em que as atividades são desenvolvidas, sob o número CAAE 00265218.5.0000.5505, com número de aprovação do parecer: 3.009.844. Todos os cuidados éticos foram respeitados.

Os participantes deste estudo somam 58 pessoas, entre estudantes com idade média de 20 anos, usuários de serviços de saúde mental, com média de idade de 32 anos, e familiares com idade média de 65 anos. Conversas informais e entrevistas semiestruturadas foram 
realizadas em salas da Universidade e se subdividiram em vários encontros após as atividades semanais regulares no Projeto Trajetórias. As reuniões ocorrem semanalmente, e os participantes chegaram ao Projeto por meio de convites realizados em eventos, reuniões e demais encontros da Frente Antimanicomial da região ou referentes à luta antimanicomial. As atividades se desenvolveram com portas abertas e acolhem qualquer interessado, valorizando os convidados dos participantes iniciais em um mecanismo de bola de neve. Assim, configurou-se um grupo de vínculos afetivos que se fortaleceram com a continuidade das ações construídas conjuntamente e que passaram a propositores e gestores, como também alguns interessados se tornaram oficineiros dentro do Projeto.

\section{Um caminho para construir novas trajetórias...}

O Projeto de extensão Trajetórias ${ }^{11}$ surgiu a partir de demanda e sugestão de participantes após finalização de pesquisa sobre ações de saúde mental na atenção básica. Elaborado como solução de compromisso entre os envolvidos, essa proposta se estruturou a partir da manutenção de um espaço de reflexão sobre o sofrimento psíquico, a rede de atenção psicossocial e a vida cotidiana.

O Projeto foi concebido a partir de diferentes experiências, em que pessoas com transtornos psíquicos graves participam de atividades acadêmicas ${ }^{14-17}$. Tomado como estudo de caso, assume como objetivo geral promover espaço de troca de saberes sobre saúde mental e direitos humanos, a partir do protagonismo de usuários e familiares de serviços de saúde mental inseridos em amplo plano de ações de ensino-aprendizagem em saúde. Também realiza encontros temáticos para circulação do saber acadêmico e de saberes advindos da experiência; valoriza diferentes saberes sobre saúde mental; resgata espaço de convívio e de produção de relações sociais; debate sobre importantes temas em saúde mental e políticas públicas; produz reflexão sobre o papel da universidade frente a grupos vulneráveis e excluídos do processo acadêmico; insere diferentes protagonistas no cenário da saúde para promover fazeres em conjunto; incentiva a produção de conhecimento coletivo e solidário; define e realiza estratégias de inclusão de usuários de serviços de saúde em diferentes espaços sociais e de expressão artística.

Os participantes regulares são estudantes de diferentes cursos, familiares e usuários de serviços de atenção psicossocial, com mais de trinta usuários em participações flutuantes. Juntos, desenvolvem atividades com múltiplas linguagens expressivas, entre as quais estão: rodas de conversa, oficinas, aulas abertas e inserções artísticas.

Os encontros semanais são realizados em uma sala de aula da Universidade, expandindo para espaços abertos e praças públicas. Ao final de um conjunto de ações, realizam-se aulas abertas que ocorrem no saguão da Universidade, momento em que a comunidade local se insere em atividades de convívio e de reflexão sobre saúde mental, rede de atenção psicossocial, espaços de cuidar e, também, sobre o combate à discriminação e a luta pelos direitos humanos.

Nas rodas de conversa, com metodologias da educação popular 20-22, ocorrem debates de questões sugeridas pelos participantes com as seguintes temáticas: cotidiano, necessidades e demandas de saúde, desafios de convívio em sociedade, família, moradia, trabalho, cidadania e direitos subtraídos. Para acessar o conhecimento e a experiência singular dos participantes, são utilizadas diferentes estratégias por meio de relatos de experiência, histórias contadas, estímulo a escritas coletivas, poesias e narrativas.

As oficinas psicossociais ${ }^{\mathbf{2 3}}$ com expressões artísticas de múltiplas linguagens revelam importante estímulo para produções expressivas individuais e coletivas. Além disso, a promoção de ações e espaços de convívio e a inserção em diferentes espaços públicos 
ampliam as trocas sociais. As expressões de arte, como estética e política ${ }^{24}$, são importantes instrumentos utilizados tanto no sentido de estimular a expressão dos participantes como de promover produção artística por meio de ações que permitam avançar na expansão da vida e aumentar a circulação na cidade.

Além disso, são elaborados manifestos, relatos individuais e coletivos, contos e poesias, em um movimento em que todos ensinam e todos aprendem em ensaio contínuo de reciprocidade e horizontalidade na produção de conhecimento, em experiência de ensino-aprendizagem, em que os envolvidos realizam ações horizontais colaborativas. Com esse amplo leque de intervenções, procura-se ampliar os modos de intermediar reflexões sobre o campo da saúde mental e a luta pelos direitos humanos, como indissociáveis. Em um trabalho constante de convite para produção de novas utopias ${ }^{25}$ comprometidas com o cuidado em liberdade, por defender que: "uma das terapias mais importantes para combater a loucura é a liberdade”26(72).

\section{Os efeitos para a formação em saúde: experiências e trajetórias}

As ações mencionadas revelam espaço de aprender e ensinar em que são descobertas diferentes nuances da cena cotidiana de viver o sofrimento psíquico intenso e de produzir formas de cuidado em liberdade. A máxima basagliana 'a liberdade é terapêutica' é bússola, por se tratar de uma experiência em que se articula o tripé universitário de ensino-pesquisa-extensão, que se revela como espaço profícuo para se pensarem novos modos de cuidar do sofrimento psíquico, em que se reafirma o compromisso de ampliar trocas sociais que sejam efetivadas para além dos recursos da Rede de Atenção Psicossocial (Raps) ${ }^{27}$.

O convite à participação dos usuários responde à reivindicação do movimento inglês denominado 'Nada sobre nós sem nós', que, na década de 1990, exigiu maior envolvimento dos usuários em todos os níveis dos serviços e também nas pesquisas que têm sua vida em análise ${ }^{\mathbf{1 4}}$. Assim, a participação dos usuários dos serviços de saúde mental e dos familiares convida periféricos olhares sobre as dimensões do sofrimento psíquico e dos desafios cotidianos. Outras iniciativas como esta destacam a relevância de se tomar o saber da experiência como produção de conhecimento relevante nesse campo ${ }^{15-17}$.

A Universidade em que ocorre esta experiência tem Projeto Político Pedagógico vocacionado à formação para o trabalho em equipe $\mathrm{e}$ para a integralidade no cuidado, comprometendo-se com a educação interprofissional para o trabalho em saúde ${ }^{28}$. Se posiciona como recurso territorial e humano, ao realizar ações nos serviços de saúde efetivadas como tecnologias leves ${ }^{29}$. Ainda que o Projeto Pedagógico ${ }^{26}$ oportunize situações para construção de um trabalho comum a partir da formação para a saúde ${ }^{12}$, os alunos relatam que os contatos com os usuários se tornam mais estreitos e intensos, o que pode ser destacado nas falas dos estudantes:

Percebemos o fazer na área da saúde, tendo esse privilégio de ter os próprios usuários nos dizendo sobre suas experiências, dando pistas do que fazer.

[...] como há bastante diálogo, todos auxiliam com o que têm de melhor.

[...] um duplo desafio-aprendizado: de, em meio a tantas demandas acadêmicas, optar por estar nos encontros semanais que propõem um novo olhar sobre para que/para quem produzimos nosso saber; e de me colocar em uma reflexão acerca das possibilidades do Serviço Social no campo da saúde mental.

[...] pude participar de diversos projetos que contribuíram de modo ímpar. Cada um acrescentou desafios, novos ol hares, prática diversas, saberes, mas ainda muito pequeninos e insignificantes frente ao rico e grande processo que vivo aqui. 
Nesse Projeto de extensão, os alunos de diferentes cursos se inserem livremente. São estudantes de terapia ocupacional, serviço social, fisioterapia e psicologia. Cabe aos estudantes compilar informações sobre Reforma Psiquiátrica, serviços de saúde mental e desafios dos serviços, e abre-se o debate nas rodas e oficinas, nas quais os temas organizados pelos estudantes encontram o saber dos usuários e familiares. Nesse encontro de saberes, estudantes vivenciam uma experiência de construção coletiva, de respeito ao conhecimento vivo, e, assim, o saber da experiência torna-se fundamental, na medida em que demanda estar junto, tocar e deixar-se tocar em momentos de intensas trocas.

Para Bondìa ${ }^{30}$, a experiência deve ser compreendida como o que "nos passa, nos acontece, nos toca", sendo necessário tempo para estar junto. É preciso tomar tempo para estar com o outro e viver o encontro de um modo mais lento, em que se possa dar tempo para conhecer o outro, o que requer

parar para pensar, parar para olhar, parar para escutar, pensar mais devagar, olhar mais devagar, e escutar mais devagar; parar para sentir, sentir mais devagar, demorar-se nos detalhes, suspender a opinião, suspender o juízo, suspender a vontade, suspender o automatismo da ação, cultivar a atenção e a delicadeza, abrir os olhos e os ouvidos, falar sobre o que nos acontece, aprender a lentidão, escutar aos outros, cultivar a arte do encontro, calar muito, ter paciência e dar-se tempo e espaço30(24).

Em tempos corridos no mundo acadêmico atual, essa proposta de seguir devagar pode parecer contramão do produtivismo que impera. Os estudantes destacam essa vivência como marcante e positiva:

Para mim, tem sido um grande aprendizado, pois percebo que sou desafiada a mudar e repensar condutas ligadas 'no automático'. Dar tempo, ir com calma, exercitar a escuta.
As atividades e oficinas nos permitem desenvolver um campo potencial de criação, de trocas e experiências. Podemos pensar esse espaço como impulsionador, nosso devaneio e imaginação. Sinto o respeito e a valorização das diferenças [...] abertura e disponibilidade ao novo.

[Ou, ainda] [...] possibilitam criar novas formas de olhar para o outro, compartilhar experiências e trocas sobre o cotidiano profissional no futuro.

Nas rodas de conversa, as ações são compartilhadas entre todos os envolvidos, e, assim, definem-se membranas menos rígidas e papéis mais flexíveis, cujo mote principal é a construção de vínculos, em uma forma relacional. As estratégias de circulação de saberes são utilizadas como pretexto e como produções de intermezzos, que se colocam na intenção maior de aproximação entre as pessoas. E, também, de constituir um corpo de conhecimento em que todos os saberes são igualmente importantes. Na perspectiva desinstitucionalizante, a transformação necessária para o trabalho em saúde mental deve se centrar na relação, por isso a aposta em rodas de conhecimento compartilhado. Os alunos destacam o que aprenderam para além de conteúdos sobre saúde mental, destacam ganhos pessoais e eventos transformadores:

[...] através desta experiência, chego à conclusão de que temos que aquietar e deixar que o encontro e as novas ideias ganhem forma e vida. É como já dizia Vinicius de Moraes: 'a vida é a arte do encontro, embora haja tanto desencontro pela vida'. Desejo que nossos encontros potencializem a luta! (estudante).

Por meio de produções coletivas textuais e artísticas, constituem-se fortes laços entre os participantes externos e os alunos extensionistas, de modo que se referem assim a essas experiências:

Esta escrita me lembra a brincadeira do telefone sem fio, onde a história do começo é totalmente diferente do final. (participante). 
Entre as produções textuais coletivas, uma das histórias finalizou assim:

Obrigado a todos pela presença, chegando no horário normal, é um dia vital para organizar a vida. E com toda pontualidade criamos uma rotina, que é partilhada por todos os participantes. Rotina que ocupa sentido junto das demais coisas do nosso tempo. Essa é a nossa vida, vivências e experiências que não acabam mais. Esses encontros, nossas trajetórias, se misturam e podemos aprender a sentir a dor de cada um de nós, assim como dividir as alegrias e bons momentos. É muito bom estar aqui. (texto coletivo).

Além de textos coletivos sobre diferentes temáticas, há o incentivo para produções singulares, como narrativas, contos e poesias. Com trabalho em poesias e por meio da ação colaborativa, dois participantes organizaram coletânea de poesias em livros artesanais, que são comercializados por eles. Esses escritos também influenciam registros dos alunos, que trazem a seguinte escrita:

Criar a magia, identificando sentimentos através das palavras e entonações, é possivelmente o caminho poético. Dar asas ao menino dentro de cada adulto, do sofrimento perante o prazer, de tornar arte o drama, de gritar calado diante dos momentos opressivos e fazer das dificuldades o entendimento. (estudante).

A inserção no espaço acadêmico desse modo de trabalhar coletivo e aberto remete à indissociabilidade entre a saúde mental e a luta pelos direitos humanos como constituintes para estimular novas utopias da realidade ${ }^{25}$ comprometidas com o cuidado em liberdade. Percebe-se a produção de espaços potentes para trocas de experiências e discussões em que a reflexão sobre as múltiplas dimensões do sofrimento psíquico ${ }^{26,29,31}$ são colocadas em pauta. Estudos que trazem essa vocação indicam a importância e a necessidade de valorizar esse saber e a participação de usuários em vários âmbitos da produção de conhecimento ${ }^{32-34}$.
Em momentos de maior mobilização, o grupo se propõe a montar uma aula aberta em composição com docentes, grupos atuantes nos serviços de saúde, projetos de estágio e demais projetos de extensão. Nesse momento, os usuários apresentam produções artísticas, realizam oficinas e compartilham a coordenação das atividades com os alunos. A valorização desse trabalho conjunto é relatada pelos alunos da seguinte maneira:

O contato com os usuários e com os familiares me fez aprender muito. Produzir esses encontros e vivê-los é estar afirmativamente na zona de fronteira. Fronteira entre a loucura e a razão, entre o patológico e o sadio, entre a clínica, cultura e a educação. Entre o agir, o calar e o falar, entre o trabalho e o lazer, entre a vida e suas muitas formas possíveis de expressão. (estudante).

A compreensão da Saúde mental como campo $^{35}$ de trabalho interprofissional em saúde, em que diferentes núcleos de conhecimento se encontram, é assinalada pelos alunos. Em adição a essa ideia, a concepção diagnóstica e simplificada do sofrimento psíquico como doença mental dá lugar à compreensão das suas múltiplas dimensões, devolvendo a complexidade do sofrimento psíquico como condição humana ${ }^{9,10}$, o que faz surgirem novas variantes sobre o modo como ele pode ser vivenciado:

Essa vivência me proporcionou a compreensão da centralidade do saber e das vivências dos usuários na elaboração das práticas em Saúde Mental e também a indissociabilidade entre o cuidado, o poder dos usuários e a luta pelos direitos. (estudante).

Durante o processo pude ver o quanto o cuidado voltado ao sujeito, e não à doença, é potente para o desenvolvimento de autonomia dos usuários e familiares. (estudante).

A defesa da dimensão relacional como pilar para novas práticas em saúde prevê um esforço 
de ultrapassar a simplificação dos complexos fenômenos humanos tomados como doença mental, para encontrar o homem e sua singularidade. Pois,

quando digo que: este indivíduo é esquizofrênico [...] relaciono-me com ele de um modo particular, sabendo que a esquizofrenia é uma 'doença' contra a qual nada se pode fazer: minha relação não irá além daquilo que se espera diante da 'esquizofrenicidade' do interlocutor(28).

Essa é uma denúncia que remete a uma transmutação nada atual, entretanto, ainda fundamental e necessária. Assim, confirma que o novo objeto da saúde mental, nomeado como "existência-sofrimento" das pessoas em relação com o "corpo social"9(30), exige imersão nas relações e experiências. O caráter inovador dessas ações reside na busca do compartilhamento de saberes, na construção de relações menos verticalizadas e no trabalho em reciprocidade, que se apresenta como uma forma possível de traduzir necessidades para construir novos percursos transformadores das condições concretas de vida. As alternativas realizadas pelos grupos de gestão autônoma de medicação também oferecem espaço ímpar para que essas vozes sejam ouvidas e legitimadas em polifonias ${ }^{36,37}$.

Esse é um desafio que se reafirma cotidianamente nos encontros com os profissionais dos serviços por eles frequentados. Transformação nada fácil, como destacada contundentemente no relato deste participante:

Acredito que todos aqui, na sala, têm boa vontade para enxergar o doente mental com outros olhos, mas chega uma hora que torna só mais um doente mental na vida de vocês. $E$, uma vez diagnosticado como doente mental, ficamos para sempre com este estigma. Eu sofro o tempo todo, posso não parecer estar sofrendo agora, mas uma parte de mim está, sempre está. (participante).

O efeito dessas falas é mola propulsora de reposicionamento por parte dos alunos frente aos desafios do trabalho interprofissional no campo da saúde mental. O convívio pode fazer retomar a complexidade do sofrimento psíquico e, também, o compromisso com o cuidado em liberdade. Ao reconstituir a complexidade do sofrimento psíquico, a ação em saúde mental se conecta a um sentido de cuidar como ocupar-se de alguém enquanto esse alguém transforma sua vida concreta e cotidiana, (re)arranjando sua vida em outros modos, distanciando do que alimenta seu sofrimento? ${ }^{9}$.

Ao se tomar esse sentido de cuidar, na perspectiva desinstitucionalizante, como central, podem-se buscar experimentações de práticas menos hierarquizadas e verdades menos sólidas, que permitem uma aventura junto aos indivíduos considerados loucos para se dar lugar à experiência de vivenciar momentos de troca de conhecimento com limites imprecisos entre os saberes produzidos no viver. Efeito exemplificado nos relatos dos estudantes:

Essa é minha busca e acredito que a de todos que participaram deste projeto: enfrentar, lutar, resistir. Ainda há muito a ser feito, ainda há muito a ser conquistado. A roda não para. Precisamos acreditar que alguma mudança já se mostra possível. (estudante).

Construímos laços e partilhamos vivências que me transformaram, além de me darem mais certeza de minha escolha profissional e do caminho que quero traçar. (estudante).

Falas como essas evidenciam o poder transformador dessa experiência para a formação de novos profissionais da saúde. Permite-se afirmar que ocorrem transformações em ambas as direções, como se destaca nos relatos sobre a importância que usuários e familiares dão às vivências e às trocas vividas nesse período, exemplificadas a seguir:

[...] gosto do que escrevemos juntos. Mas precisamos nos organizar, buscar espaço na internet, outro 
tipo de público. Vai ter quem goste e quem queira tacar tomates, mas temos que enfrentar quem denegrir o teor de nosso trabalho. Nossas ideias, poesias são ricas. Alguns são simples demais, mas explorar as próprias limitações é uma riqueza do ser humano. Todo ser humano tem potências, mas cada um tem um percurso, um mais retilíneo e outro com muitos obstáculos. (participante).

Trajetórias... Cada um de nós trouxe as suas. $E$ fomos trançando, trocando, ouvindo e falando. Hoje percebemos que não estamos mais sozinhos. Temos uns aos outros. (familiar).

Nunca imaginei que um dia estivesse na Universidade, e hoje participar das conversas de Saúde Mental aqui é bom para mim. Pensava que era para ricos. Estou gostando porque aconteceu comigo. (participante).

Aqui é um espaço de trocas, experiências e partiIhas... meus amigos estão aqui na Universidade e não só lá no Naps. (participante).

A gente aprende a viver, aprende a sorrir, aprende a sonhar e leva isso para vida da gente. (participante).

Podem-se destacar efeitos em duas direções. Por um lado, o trabalho coletivo afetou diretamente outras dimensões da vida dos usuários, proporcionando espaço de exercício de cidadania, além da compreensão de seus direitos. Participantes, usuários e familiares passaram a desenvolver maior senso crítico e a construir novos espaços para exercício do poder contratual e autonomia ${ }^{38}$.

Por outro lado, no âmbito da formação para o trabalho em saúde, os alunos passaram a duvidar das certezas científicas sobre o sofrimento psíquico, tomado como transtornos mentais ou síndromes psiquiátricas distantes da vida das pessoas que as vivenciam. Ambos experimentaram momentos de alegria, de crescimento mútuo, de trocas afetivas, que são elementos fundamentais para insurgirem novos fazeres em saúde.

\section{Considerações finais}

A pesquisa apresentou diferentes passagens, em que se confirma o protagonismo de pessoas com sofrimento psíquico intenso, usuários de serviços de saúde mental, nas ações de ensino-aprendizagem em saúde. Também desperta para a produção compartilhada de conhecimentos, que foi intensificada no espaço acadêmico. Além disso, ilustra o crescimento mútuo e a importância do compartilhamento de conhecimento sobre saúde mental, seus atores, estratégias de cuidado e o valor do saber da experiência nesse contexto.

Entre seus efeitos, os dados revelam que essa proposta vem possibilitando o aumento da reflexão política dos participantes, levando-os a se manterem atentos aos seus direitos negados e/ou perdidos. Em consequência, fortalecem-se para a defesa e se posicionam de modo mais exigente em alguns momentos, recusando o contentamento frente ao que recebem como conquistas de direitos que lhes pertencem e não deviam ser a eles negados.

Foi através da pesquisa que o Projeto de extensão Trajetórias teve início. Foi por meio das ações de ensino que ele se fortaleceu e vem se confirmando sustentado no tripé universitário. Assim, toma a produção de conhecimentos como modo de retroalimentar novas pesquisas e projetos com a participação dessas pessoas, nesse espaço profícuo para o debate de ideias.

Pode-se perceber que a experiência de aprender-ensinar com a participação de usuários e familiares vem transformando a compreensão do sofrimento psíquico, assim como as práticas no campo da saúde mental a partir da concepção de integralidade e do sentido de trabalho interprofissional em saúde. $\mathrm{E}$, principalmente, tem aproximado os futuros trabalhadores da saúde do cotidiano de pessoas que vivem a condição de sofrimento psíquico intenso sobre pilares relacionais e horizontais.

Os desafios emergem principalmente da condução de encontros com metodologias abertas para além dos momentos e espaços proporcionados pelo Projeto em si. Também 
*Orcid (Open Researcher and Contributor ID). não é fácil dar visibilidade à produção de conhecimento dos participantes. Somam-se inúmeros manuscritos elaborados que não encontram espaço para publicação e divulgação. Avolumam-se poesias, breves instrutivos, cadernos com novos conceitos, narrativas e demais fragmentos de produção coletiva que exigem encontrar espaço para divulgação. A

\section{Referências}

1. Foucault M. História da Loucura. 2. ed. São Paulo: Perspectiva; 1987

2. Foucault M. O nascimento da clínica. Rio de Janeiro: Forense; 1977

3. Silva Filho JF. A medicina, a psiquiatria e a doença mental. In: Tundis AS, Costa NR, organizadores. Cidadania e Loucura. Políticas de Saúde mental no Brasil. Petrópolis: Vozes/Abrasco; 1987. p. 75-102.

4. Basaglia F. Corpo e Instituição: considerações antropológicas e psicopatologias em psiquiatria institucional. In: Basaglia F. Escritos selecionados em saúde mental e reforma psiquiátrica. Rio de Janeiro: Garamond; 2005. p. 73-90.

5. Basaglia F. A instituição negada. São Paulo: Graal; 1985.

6. Bezerra JR. A psiquiatria contemporânea e seus desafios. In: Zorzaelli R, Bezerra Jr. B, Costa JF, organizadores. A criação de diagnósticos na psiquiatria contemporânea. Rio de Janeiro: Garamond; 2014. p. 9-34. busca de parcerias para dar visibilidade a essas produções coletivas é o empreendimento atual.

\section{Colaboradora}

Moreira MIB (0000-0001-5798-2023)*é responsável pela elaboração do manuscrito.
7. Basaglia F. Poder e violência no Hospital Psiquiátrico. In: Basaglia F. A Psiquiatria Alternativa: contra o pessimismo da razão, o otimismo da prática. São Paulo: Brasil Debates; 1982. p. 83-91.

8. Basaglia F, Ongaro FB. Los Crimes de La paz: investigacion sobre los intelectuales y los técnicos como servidores de la opresion. Buenos Aires: Siglo Veintiuno Editores; 1977.

9. Rotelli F, Leonardis O, Mauri D. Desinstitucionalização, uma outra via. In: Rotelli F. Desinstituconalização. São Paulo: Hucitec; 2000. p. 17-60.

10. Rotelli F. A instituição inventada. In: Rotelli F. Desinstitucionalização. São Paulo: Hucitec; 2000. p. 8999

11. Moreira MIB, Martins LFS, Celeste AC, et al. Trajetórias: protagonismo de usuários de serviços de saúde mental nas ações de ensino-aprendizagem em saúde. In: Anais do $2^{\circ}$ Encontro de Saúde Mental; 2016 dez 2; São Paulo. São Paulo: Universidade Federal de São Paulo; 2016. 
12. Medeiros M AT, Braga-Campos FC, Moreira MIB. A integralidade como eixo da formação em proposta interdisciplinar: estágios de Nutrição e Psicologia no campo da Saúde Coletiva. Rev. Nutr. [internet]. 2014 [acesso em 2020 ago 14]; 27(6):785-798. Disponível em: http://www.scielo.br/scielo.php?script=sci_ arttext\&pid=S1415-52732014000600785\&lng=en.

13. Moreira MIB, Onocko-Campos RT. Ações de saúde mental na rede de atenção psicossocial pela perspectiva dos usuários. Saúde Soc. [internet]. 2017 [acesso em 2020 ago 14]; 26(2):462-474. Disponível em: http://www.scielo.br/scielo.php?script=sci arttext\&pid=S0104-12902017000200462\&lng=en. 14. Phillips R. Consumer Participation in Mental Health Research. Soc. Pol. Journal New Zel. 2006; 27: 71182.

14. Escola de Saúde Pública do Estado de Minas Gerais; Associação dos Usuários dos Serviços de Saúde Mental de Minas Gerais. Saúde Mental em Letras Mineiras. Belo Horizonte: Autêntica; 2010.

15. Leal EM, Serpa Junior OD. Acesso à experiência em primeira pessoa na pesquisa em Saúde Mental. Ciênc. Saúde Colet. [internet]. 2013 [acesso em 2020 ago 14]; 18(10):2939-2948. Disponível em: http://www.scielo.br/scielo.php?script=sci arttext\&pid=S1413-81232013001000018\&lng=en. https://doi.org/10.1590/S1413-81232013001000018.

16. Passos E, Otanari T MC, Emerich BF, et al. O Comitê Cidadão como estratégia cogestiva em uma pesquisa participativa no campo da saúde mental. Ciênc. Saúde Colet. [internet]. 2013 [acesso em 2020 ago 14]; 18(10):2919-2928. Disponível em: http://www. scielo.br/scielo.php?script=sci_arttext\&pid=S1413$-81232013001000016 \& \operatorname{lng}=$ en.

17. Minayo MCS. O desafio do conhecimento: Pesquisa qualitativa em saúde. 6. ed. Rio de Janeiro: Abrasco; 1999.

18. Yin RK. Estudo de Caso. Planejamento e métodos. 5. ed. Porto Alegre: Bookman; 2015.
19. Freire P. Pedagogia do Oprimido. 18. ed. Rio de Janeiro: Paz e Terra Educação; 1988.

20. Freire P. Pedagogia da autonomia: saberes necessários à pratica educativa. 23. ed. Rio de Janeiro: Paz e Terra Educação; 2002.

21. Freire P. Ação cultural para a liberdade e outros escritos. 9. ed. Rio de Janeiro: Paz e Terra Educação; 2001.

22. Afonso L. Oficinas: um método de intervenção psicossocial. Belo Horizonte: Edições campo social; 2002.

23. Rancière J. A partilha do sensível: estética e política. 34. ed. São Paulo: EXO experimental; 2005.

24. Basaglia F. A utopia da realidade. In: Basaglia F, organizador. Escritos selecionados em saúde mental e reforma psiquiátrica. Rio de Janeiro: Garamond; 2005. p. 225-236.

25. Basaglia F. A Psiquiatria Alternativa: contra o pessimismo da razão, o otimismo da prática. Conferências no Brasil. São Paulo: Brasil Debates; 1982.

26. Brasil. Ministério da Saúde. Portaria $n^{0} 3.088$, de 23 de dezembro de 2011. Institui a Rede de Atenção Psicossocial para pessoas com sofrimento ou transtorno mental e com necessidades decorrentes do uso de crack, álcool e outras drogas, no âmbito do Sistema Único de Saúde (SUS). Diário Oficial da União [internet]. 24 Dez 2011. [acesso em 2020 ago 14]. Disponível em: http://bvsms.saude.gov.br/bvs/saudelegis/ gm/2011/prt3088_23_12_2011_rep.html.

27. Universidade Federal de São Paulo. A educação interprofissional na formação em saúde: a competência para o trabalho em equipe e para a integralidade no cuidado. Santos: UNIFESP; 2006.

28. Merhy EE. Em Busca de Ferramentas Analisadoras das Tecnologias em Saúde: a informação e o dia a dia de um serviço, interrogando e gerindo trabalho em saúde. In: Merhy EE, Onocko R, organizadores. Agir em saúde: um desafio para o público. São Paulo: Hucitec; 2006. p. 113-150. 
29. Bondìa JL. Notas sobre a experiência e o saber de experiência. Rev. bras. educ. 2002; 19:20-28.

30. Brasil. Ministério da Saúde. Cadernos de Atenção Básica n. 34. [internet]. Brasília, DF: Ministério da Saúde; 2013. [acesso em 2020 ago 18]. Disponível em: http://bvsms.saude.gov.br/bvs/publicacoes/cadernos_atencao_basica_34_saude_mental.pdf.

31. Serpa Junior O, Campos RO, Malajovich N, et al. Experiência, narrativa e conhecimento: a perspectiva do psiquiatra e a do usuário. Physis (Rio J.). 2014; 24(4):1053-1077.

32. Cardoso MRO, Oliveira PTR, Piani PPF. Práticas de cuidado em saúde mental na voz dos usuários de um Centro de Atenção Psicossocial do estado do Pará. Saúde debate. [internet]. 2016 [acesso em 2020 ago 14]; 40(109):86-99. Disponível em: http://www.scielo.br/scielo.php?script=sci arttext\&pid=S0103-11042016000200086\&lng=pt. https://doi.org/10.1590/0103-1104201610907.

33. Emerich BF, Onocko Campos R, Passos E. Direitos na loucura: o que dizem usuários e gestores dos centros de atenção psicossocial (Caps). Interface comun. saúde educ. 2014; 18(51):685-696.

34. Campos GW. Saúde pública e saúde coletiva: campo e núcleo de saberes e práticas. Ciênc. Saúde Colet. 2000; 5(2):219-230.
35. Gonçalves LLM, Campos RTO. Narrativas de usuários de saúde mental em uma experiência de gestão autônoma de medicação. Cad. Saúde Pública [internet]. 2017 [acesso em 2020 ago 14]; 33(11):1-11. Disponível em: http://www.scielo.br/scielo.php?script=sci arttext\&pid=S0102-311X2017001105002\&lng=en.

36. Rodriguez BL, Benisty L, Richard P, et al. Gestão Autônoma da Medicação (GAM): novas perspectivas sobre bem-estar, qualidade de vida e medicação psiquiátrica. Ciênc. Saúde Colet. [internet]. 2013 [acesso em 2020 ago 14]. Disponível em: http://www. cienciaesaudecoletiva.com.br/artigos/gestao-autonoma-da-medicacao-gam-novas-perspectivas-sobre-bemestar-qualidade-de-vida-e-medicacao-psiquiatrica/13173?id=13173.

37. Kinoshita RT. Contratualidade e reabilitação psicossocial. In: Pitta A, organizadora. Reabilitação psicossocial no Brasil. 2. ed. São Paulo: Hucitec; 2001. p. 5569.

Recebido em 01/03/2020

Aprovado em 18/08/2020

Conflito de interesses: inexistente

Suporte financeiro: Universidade Federal de São Paulo 